\title{
Comportamentos tradutolóxicos, feminismos e literatura infantoxuvenil: algunhas calas no ámbito galego ${ }^{1}$
}

\author{
Montse Pena Presas ${ }^{2}$ \\ Recibido: 27 de xaneiro de 2020 / Aceptado: 16 de maio de 2020
}

Resumo. Este artigo analiza o campo literario infantoxuvenil galego a partir das pegadas que os feminismos e as traducións tiveron nel. A partir do establecemento previo dunha serie de períodos no referente ao impacto dos feminismos nas obras para a infancia e a mocidade, tentarase ver se as obras feministas doutros sistemas literarios precederon e foron modelo das galegas no marco da literatura infantil e xuvenil, se as autoras comprometidas cos feminismos en Galicia foron tamén tradutoras de textos coeducativos e se na actualidade o campo literario galego conta coas obras referenciais na abordaxe de cuestións como as masculinidades alternativas, as identidades sexuais non normativas ou os personaxes *trans. Grazas á análise de casos concretos, comprobarase que o campo literario galego tardou en importar obras feministas para o lectorado en formación, que as obras galegas souberon ser innovadoras con respecto aos feminismos -aínda que nalgunhas delas se perciba a influencia de certos modelos- e que, no tempo en que se precisaban traducións pola entrada do galego no ensino, privilexiáronse os textos das tradicións populares veciñas e os clásicos da literatura infantil. Ademais, incidirase en que, nos últimos anos, a tradución de autoras é algo moi habitual, mentres que tamén se conta con algúns textos feministas interesantes, mais isto ocorre sen ningún tipo de planificación previa que garanta unha calidade e os mecanismos de diversidade cultural que un sistema literario coas particularidades do galego precisa.

Palabras chave: tradución; feminismos; literatura infantoxuvenil; sistema literario galego.

\section{[es] Comportamientos tradutológicos, feminismos y literatura infantojuvenil: algunas calas en el ámbito gallego}

Resumen. Este artículo analiza el campo literario infantojuvenil gallego a partir de las huellas que los feminismos y las traducciones dejaron en él. A partir del establecimiento previo de una serie de períodos en lo referente al impacto de los feminismos en las obras para la infancia y la juventud, se intentará ver si las obras feministas de otros sistemas literarios precedieron y fueron modelo de las gallegas en el marco de la literatura infantil y juvenil, si las autoras comprometidas con los feminismos en Galicia fueron también traductoras de textos coeducativos y si en la actualidad el campo literario gallego cuenta con las obras referenciales en el abordaje de cuestiones como las masculinidades alternativas, las identidades sexuales no normativas o los personajes *trans. Gracias al análisis de casos concretos, se comprobará que el campo literario gallego tardó en importar obras feministas para el lectorado en formación, que las obras gallegas supieron ser innovadoras con respecto a los feminismos -aunque en algunas de ellas se perciba la influencia de ciertos modelos- y que, en el tiempo en el que se necesitaban traducciones por la entrada del gallego en la enseñanza, se privilegiaron textos de las tradiciones vecinas y los clásicos de la literatura infantil. Además, se incidirá en que, en los últimos años, la traducción de autoras es algo muy habitual, mientras que también se cuenta con algunos textos feministas interesantes, pero esto ocurre sin ningún tipo de planificación previa que garantice una calidad y los mecanismos de diversidad cultural que un sistema literario con las particularidades del gallego necesita.

Palabras clave: traducción; feminismos; literatura infantojuvenil; sistema literario gallego.

\section{[en] Tradutological Behavior, Feminisms and Literature for Children and Young Adults: some Examples from the Galician Sphere}

1 A autora agradece a Ana Luna e Dolores Vilavedra as suxestións e comentarios realizados nas primeiras versións deste artigo.

2 Universidade de Santiago de Compostela. Departamento de Didácticas Aplicadas.

Correo-e: montserrat.pena@usc.es; https://orcid.org/0000-0001-5565-5408. 
Abstract. This article discusses Galician Literature for Children and Young Adults from the traces that feminism and translations left in it. A series of periods regarding the impact of feminism on books for children and young adults were established in an attempt to study whether feminist texts from other literary systems preceded and served as models within the Galician frame of literature for children and young adults; whether authors committed to feminism in Galicia were also translators of coeducational texts; and whether at present the Galician literary field has reference works in approaching issues such as alternative masculitines, sexual identities or *trans-characters. By analysing particular cases, it will be confirmed, first, that Galician literature took time to import feminist works for young readers; second, that Galician works were innovative with regard to feminism -although some of them reflect the influence of certain models-; and, third, that in times when translations were needed due to the access of Galician language to Teaching, texts from nearby traditions or from Children's classic literature were privileged. In addition, stress will be on the fact that, recently, translation of women authors is becoming more and more frequent at the same time that we can count on several interesting feminist texts. However, this is happening without any prior planning which may guarantee the quality and the mechanisms for cultural diversity that a literary system with the particularities of the Galician one would need.

Keywords: Translation; Feminism; Children's and Young Literature; Galician Literary System.

Sumario. 1. A tradución como parte da historia literaria galega: reconfigurar os mapas dende o campo literario e os feminismos. 2. Algunhas consideracións previas sobre literatura infantoxuvenil, feminismos e tradución. 3. Percorrer o mapa: unha posible periodización partindo de literatura infantoxuvenil, feminismos e tradución. 3.1. Etapa inicial (1927-1980): escasos libros infantís, escasas traducións e algunhas pioneiras. 3.2. Etapa militante (1981-1989): entre o impacto dos feminismos nos textos galegos e a escasa presenza de obras feministas traducidas. 3.3. Etapa de xeneralización de protagonistas femininas (1990-2005) e da aposta pola tradución de autoras. 3.4. Etapa ecléctica (2006-2016): entre a a innovación dos textos galegos e a tradución das obras clásicas da coeducación. 4. Conclusións: transformar os mapas. 5. Referencias bibliográficas.

Como citar: Pena Presas, M. (2020): “Comportamentos tradutolóxicos, feminismos e literatura infantoxuvenil: algunhas calas no ámbito galego", en Madrygal. Revista de Estudios Gallegos 23 Núm. Especial, pp. 251-266.

\section{A tradución como parte da historia litera- ria galega: reconfigurar os mapas dende o campo literario infantoxuvenil e os feminis- mos}

En non poucas ocasións, nun achegamento sociolóxico a un campo literario concreto, esquécese -e, evidentemente, ese esquecemento non é casual, porque vén moi determinado polo tradicional peso das historias nacionais das literaturas- que as obras traducidas, en tanto fenómenos culturais, forman tamén parte do campo literario que se está a analizar. Mesmo, indo un pouco máis alá, poderíase dicir que as obras que non foron traducidas tamén constitúen, en certa medida, pegadas que delimitan con maior precisión ese territorio que estamos a explorar.

Porén, en contados casos, nas análises marco que se teñen feito da literatura galega contempláronse as traducións como parte inherente e indispensable para a súa análise. Tan só en situacións moi concretas, quizais levados pola procurada modernidade de cultura B que pretende destacar, nunha tentativa tamén de marcar a excepcionalidade galega (a maior parte das veces fronte ao castelán), convidouse a formar parte ás traducións da historia literaria de noso. Posiblemente, o caso mellor coñecido sexa o da famosa tradución que Otero Pedrayo fixo dalgúns fragmentos do Ulyses de James Joyce, un esforzo que ten sido amosado como símbolo da cultura europeísta dos homes de Nós en multitude de ocasións.

Precisamente porque cómpre revisar como se constrúen os estudos sociohistóricos, ás veces é preciso reformulalos e recorrer ao mapa xa trazado para reconfiguralo e amplialo, abrindo quizais outros posibles camiños. Por isto, esta achega pretende partir de traballos anteriores que cinguiron literatura infantoxuvenil e feminismos en Galicia (fundamentalmente Pena Presas 2018a), arrequecida polos numerosos estudos de tradución en Galicia (especialmente, das achegas de Aurora Fernández, Iolanda Galanes, Ana Luna e Silvia Montero), para facer algunhas calas no triángulo que cingue libros para a rapazada, estudos feministas e tradución en Galicia. Se a crítica feminista se desvelou como unha ferramenta ben potente para mostrar diferentes compoñentes ideolóxicos do sistema cultural, as traducións literarias poden resultarlle un eido especialmente fértil, dado que:

...resulta ser un campo moi atractivo para proceder ao estudo dos comportamentos ideolóxicos dos diferentes mediadores que interveñen no proceso tradutor. $\mathrm{O}$ tradutor non é o único responsable do produto (nin do proceso) que se lle ofrece á comunidade receptora. A responsabilidade (ou a autoría, nun sentido máis amplo do termo) da tradución en formato libro que presenta no mercado editorial, non é exclusiva da persoa que traduce, senón que existen "outros mediadores" (editores sobre todo, iniciadores, os mecenas en definitiva) que ademais de intervir (de maneira máis ou menos directa) no proceso tradutor, teñen a autoridade para incidir 
no resultado (Garrido Vilariño 2005: 35, apud Luna Alonso e Montero Küpper 2006: 12).

As motivacións para levar este achegamento a cabo parten da reflexión arredor da nosa propia historiografía literaria, mais tamén da conciencia de que esta abordaxe socio-ideolóxica ten unha implicación evidente dende a perspectiva ética, que pasa pola conformación dunha cidadanía igualitaria (para a que os libros infantís poden ser un lugar pedagóxico máis en que contrarrestar os elementos patriarcais presentes nas nosas sociedades). Especialmente, tendo en conta o manifestado por Castro e Ergun (2017: 1), "the future of feminisms is in the transnational and the transnational is made thorough translation".

Esta primeira achega abordarase, a partir da exemplificación de casos concretos, analizando se as autoras e autores comprometidos cos feminismos foron axentes de importación de obras que se poden considerar como feministas, así como tamén se o campo literario infantil e xuvenil galego se ocupou de planificar a tradución de obras significativas dende esta perspectiva $^{3}$. Para levar a cabo esta análise, recorrerase ás etapas marcadas previamente (Pena Presas 2018a: 59-145) sobre a evolución e a pegada dos feminismos na literatura infantil e xuvenil galega.

\section{Algunhas consideracións previas sobre li- teratura infantil, feminismos e tradución}

A LIX foi un ámbito en que as autoras axiña se implicaron na creación, posiblemente porque tanto as mulleres como a infancia compartiron o seu estatus de persoas con difícil acceso ao mundo do poder. En certa maneira, tanto a literatura infantoxuvenil como a literatura escrita por mulleres sempre foron os espazos dunha certa clase de marxinados e marxinadas: a infancia -como grupo social que xorde tardiamente, xa no século XVIII (Shavit 1986: 3-5)e as mulleres que escribían, cuxa eclosión como colectivo non se produciu ata o chamado período victoriano no ámbito literario inglés. De feito, a tradición crítica nesta lingua (Nodelman 1988: 31-34; Paul 1987: 186-202) ten sinalado a relación existente entre a literatura escrita por mulleres e a literatura infantil, dado que ambas son ámbitos en que os reprimidos triunfan, a partir do equilibrio entre o acatamento ás normas e o desafío ás convencións sociais que normalmente se atopa nestes textos. Lémbrese tamén que, no contexto galego, Blanco (1990: 190-191) apuntaba algo semellante, insistindo na preferencia das autoras polo que se sitúa na periferia. A relación entre infancia e mulleres vai, como se comproba, nun sentido bidireccional: as voces destes colectivos son sempre marxinais e, polo tanto, coinciden na súa procura de seren escoitadas e lexitimadas.

Este situarse nas marxes semella funcionar tamén no ámbito das mulleres tradutoras, dado que a tradución funcionou tamén como unha vía de escape para determinadas mulleres ás que o establishment patriarcal non lles facilitou ser autoras (Fernández e Luna Alonso 2020: 8), especialmente en épocas en que estas tiñan menos peso no sistema literario. Curioso é, ademais, que cando unha muller ten a liberdade de escoller que traduce, en non poucas ocasións elixe traducir os textos literarios doutras mulleres, nun binomio no que se mestura o gusto propio, mais tamén os motivos éticos e políticos (Luna Alonso 2017: 48). A pesar de que este artigo non se centra niso, convén lembralo para decatarse logo de que, a medida que a pegada dos feminismos na LIX se fai máis visible, o número de tradutoras que se ocupan de verter ao galego textos de escritoras aumenta considerablemente e as súas estratexias tamén sofren variacións.

\section{Percorrer o mapa: unha posible periodi- zación partindo de literatura infantoxuve- nil, feminismos e tradución}

Atendendo a diferentes elementos sociais que incidiron na conformación do campo literario infantoxuvenil galego, pero sobre todo prestando atención a como o feminismo e o valor da igualdade se foi manifestando nos textos literarios, establecéronse, como xa se sinalou previamente, diferentes etapas (Pena Presas 2018a: 63-64):

\footnotetext{
Se ben Castro (2020: 52-53) sinala que as autoras feministas non son as únicas que interesan aos estudos feministas de tradución, porque calquera autora pode erixirse en obxecto de estudo da teoría feminista, considerouse que nesta primeira análise era máis acaído centrarse unicamente nestas, dado que se traballa con etapas dentro dun campo literario marcadas, precisamente, por como os feminismos incidiron nos textos.
} 
1. 1927-1980. Etapa inicial: publicación de obras illadas cunha concepción androcéntrica do mundo, caracterizada porque nelas existe unha moi cativa publicación de textos literarios para a infancia e a mocidade en galego, que amosan unha concepción da sociedade puramente tradicional.

2. 1981-1989. Etapa militante: a segunda onda feminista e a súas manifestacións na LIX, período en que o campo literario infantoxuvenil comeza a desenvolverse, o que coincide coas primeiras mostras palpables da influencia do movemento feminista nas distintas obras.

3. 1990-2005. Etapa de xeneralización de modelos de protagonistas nenas e mulleres, período moi heteroxénero en que tras o ronsel de dúas instancias autoriais, Fernández Paz e Aleixandre, aumentan as figuras femininas en todas as franxas lectoras, se ben se tende a reducir a "ideoloxía explícita" dos textos literarios.

4. 2006-2016. Etapa ecléctica: a pegada do feminismo e a súa interacción con outras subxectividades. O tempo de repensar a masculinidade e as personaxes lesbianas e gays ${ }^{4}$.

A continuación, abordaranse os diferentes períodos actualizando algúns datos e poñendo o foco en certos movementos tradutolóxicos. Debido a isto, a denominación das etapas mudará en parte, co gallo de visibilizar os elementos pertencentes ao ámbito da tradución.

\subsection{Etapa inicial (1927-1980): escasos libros infantís, escasas traducións e algunhas pio- neiras}

Esta primeira etapa caracterízase pola publicación de textos soltos que, de xeito anecdótico, irán dinamizando paseniñamente o ámbito da literatura para a infancia e a mocidade en galego. Trátase dun abano temporal moi amplo, que inclúe o breve período anterior ao estalido da Guerra Civil, a posguerra e o principio da etapa democrática, co tímido comezo da introdución do galego no ensino.

Alén das dúas obras iniciáticas por antonomasia (Margarida a do sorriso d'aurora de Correa Calderón e Memorias dun neno labrego de Xosé Neira Vilas), o final deste período resulta moito máis dinámico grazas á convocatoria dos premios de contos infantís (1968) e de teatro (1973) da asociación cultural O Facho da Coruña. En xeral, as obras desta etapa amosan unha concepción patriarcal do mundo.

A tradución de libros infantís e xuvenís neste período (a pesar de que os finais del amosan tamén unha tímida galeguización social, froito dos cambios legais, como o Decreto de bilingüismo de 1979) é practicamente anecdótica, se ben destaca o fito da colaboración entre a editorial Galaxia e a catalá La Galera, que editaron conxuntamente diferentes títulos da colección "A Galea de ouro" e "Desplega velas" (Domínguez 2008) e que, como é sabido, traduciu para o galego Xohana Torres na editorial Galaxia. Cómpre deterse na súa figura porque Torres foi tamén, como se demostra no período seguinte, unha das pioneiras na introdución do feminismo nos textos infantís. De feito, é moi posible que os homes de Galaxia lle encargasen esta tarefa porque era das poucas mulleres achegada ao seu grupo e posiblemente reproducisen, como xa se dixo noutro lugar (Pena Presas 2010: 46), a concepción patriarcal que cingue mulleres e literatura infantil, porque se pensaba que as mulleres, polo seu natural "instinto maternal" estaban máis achegadas a este tipo de público (como o demostra que no ano 1979 a autora volva colaborar coa editora, neste caso nas versións da colección infantil "A Galera", constituída maioritariamente por adaptacións de contos populares). De feito, a traxectoria como tradutora de Torres foi discontinua e estivo marcada polas necesidades do campo literario infantil e xuvenil galego. Sorprende tamén que unha creadora como ela, que se dedicou preferentemente ao público adulto, non se ocupase de verter ao galego ningún texto para este tipo de lectorado.

4 Cando se publicou este estudo, en 2018, había escasos meses que saíra do prelo a obra 22 segundos (2017) de Eva Mejuto, a primeira que no ámbito galego abordaba a cuestión das mozas e mozos trans. A partir da súa publicación, outras autoras, como María Reimóndez con Fóra do normal (2018) ou Iria Misa con Mamá, quero ser Ziggy Stardust (2018), abordaron esta cuestión para a mocidade e mesmo Miguel Ángel Alonso o fixo para a infancia co álbum ilustrado Piratas no recreo (2018). Por todo isto, proponse que a etapa ecléctica dure ata 2016. En 2017, comezaría o que se podería chamar, de xeito moi provisorio, a "etapa trans*", non unicamente polos personaxes transxénero, senón porque nas obras aparecen numerosas subxectividades en transición dende diferentes perspectivas. 
A presenza de autoras de literatura infantil e xuvenil, como poden ser Pura e Dora Vázquez, Anisia Miranda, a propia Torres ou María Victoria Moreno ${ }^{5}$ como "tradutoras pioneiras" (Luna Alonso 2017: 150) serve tamén de orientación para sinalar que estas mulleres seguramente eran conscientes de estar a contribuír a un campo literario nacente en Galicia, mais tamén de que o facían dende as marxes. Dende as marxes lingüísticas (así podemos entender que as irmás Vázquez autotraduzan ao galego, para visibilizadas, varias das pezas dramáticas escritas por ambas as dúas e recollidas en Monicreques. Teatro infantil galego, volume de 1974), mais tamén dende as marxes da súa posición de creadoras incipientes dun ámbito, o da literatura infantil e xuvenil, no que moi poucas persoas crían en Galicia e no que ser lidas fóra era aínda máis complicado. O caso de Anisia Miranda é especialmente indicativo disto, dado que Neira Vilas ten admitido que o seu propio interese pola LIX deveu do traballo realizado en Cuba cos libros para nenos e nenas por parte de Miranda, que foi tamén quen o alentou a pensar nun libro para a mocidade. A autora, ademais, parecía ser consciente e verse afectada polos prexuízos que, arredor da literatura para a infancia, circulaban na sociedade do seu tempo:

No me he dedicado a la literatura infantil porque no tengo hijos, cosa que suele suceder por ahí. Me dedico a esto como tarea revolucionaria, en su más alto sentido, porque pienso que es una de las formas de ayudar a crear ese nuevo hombre con el que soñamos. (Pena Presas 2016b: 157)

\section{Etapa militante (1981-1989): entre o im- pacto dos feminismos nos textos galegos e a escasa presenza de obras feministas tradu- cidas}

Os comezos dos anos oitenta vanse caracterizar, a nivel xeral, pola consolidación do marco legal, que posibilitou que non só se ensinase lingua galega nas escolas e nos institutos, senón que esta fose a lingua vehicular en diferentes materias. Isto sucedeu grazas á promulgación do Estatuto de Autonomía en 1981, que recoñecía o galego como lingua propia de Galicia, e en concreto, pola súa concreción na Lei de normalización lingüística de 1983. A partir deste momento, multiplícanse os espazos onde publicar libros infantoxuvenís en galego, nun proceso que comezara timidamente na época anterior. Lémbrese, igualmente, que os primeiros anos oitenta foron o tempo en que o movemento feminista, e á súa par, para a cuestión que interesa, os movementos de renovación pedagóxica, contaron cun maior impacto en Galicia, o que se pode observar nas múltiples creacións de colectivos guiados pola teima en acadar a igualdade nas escolas (Pena Presas 2018: 31-34).

É así como neste tempo se constatará a renovación temática iniciada por diferentes autoras (como por exemplo Helena Villar Janeiro ou Úrsula Heinze, que introducen nas súas narracións o misterio e as aventuras protagonizadas por un grupo de rapaces e rapazas, nunha serie de obras que poderían pertencer ao subxénero do realismo cotián), co que isto supón de normalización dun feito que ata este momento era practicamente inédito. Ademais, resulta innegable que as autoras experimentarán amplamente nesta etapa ensaiando diferentes formatos, entre os que están o conto infantil e a novela xuvenil feminista. $O$ primeiro que pode denominarse así é Pericles e a balea (1984) de Xohana Torres, mais a el seguirán, por data de publicación, obras como $O$ segredo da pedra figueira (1985) de María Xosé Queizán, O rei da nada e outros contos (1986) de Sabela Álvarez ou Anagnórise (1989) de María Victoria Moreno.

Curiosamente, tres destas autoras (agás María Xosé Queizán ${ }^{6}$ ) funcionarán tamén como tradutoras de literatura infantil e xuvenil nesta etapa. $\mathrm{O}$ aumento de traducións neste período é máis que evidente, o que se debe a esa necesidade de libros en galego para o lectorado infantil e xuvenil debido a esa entrada do galego no ensino. Por este motivo, a colaboración

5 Desta autora ocuparémonos no seguinte apartado, dado que a maioría da súa obra infanto-xuvenil e as súas traducións se desenvolveron no período seguinte.

6 Mesmo isto pode deberse a que nesa altura, Queizán era a que tiña unha obra literaria máis consolidada e estaba implicada de maneira evidente co movemento feminista e co seu pensamento, como se mostra na publicación dos ensaios Recuperemos as mans (1980) e A muller galega no ensino (1981). Igualmente, desas catro autoras, era a menos implicada coa literatura infantil, dado que ata o momento dera ao prelo tan só unha obra de ficción para a mocidade. A súa achega viña máis como creadora de novas ficcións, quizais porque conseguira xa rachar co teito de cristal do sistema literario, polo menos para posicionarse como autora. 
de diferentes axentes do sistema nesta tarefa resulta fundamental, mais as obras que se verten ao galego son, basicamente, os asumidos como clásicos da literatura infantil. Bo exemplo disto pode ser a tradución de contos como O soldadiño de chumbo (1983), editado n'A Chalupa $^{7}$ de Galaxia e traducido por Rosa García Vilariño; ou As aventuras de Alicia no País das Marabillas, traducido por Teresa Barro e Fernando Pérez-Barreiro, publicado na colección Xabarín (actualmente Xabaril) de Xerais en 1984 e merecedor do Premio Nacional de Tradución que convoca o Ministerio de Cultura. A aposta tradutolóxica irá tamén, aínda que en menor medida, por autores contemporáneos da Península, como se pode ver nas versións que Carlos Casares ou Xavier Costa Clavell realizan para a editora Argos Vergara (de textos como os de Joan Manuel Gisbert ou Carme Solé) ou nun tímido comezar no noso ámbito do álbum ilustrado importado, como é o caso da popular serie de "Teo", creada polo colectivo Violeta Denou ${ }^{8}$, con algúns volumes traducidos por Miguel Anxo Fernán Vello. Dentro das novidades con alento feminista, quizais cumpriría resaltar as populares tiras de Mafal$d a$ de Quino (coas súas disquisicións filosóficas ou coas súas preguntas á nai sobre por que a súa vida se basea no traballo doméstico), en tradución de Ramón Noreña e Xoán R. Díaz na editora luguesa Souto (e publicadas entre 1984 e 1988). De todos os xeitos, habería que debater moito sobre se estas tiras van dirixidas a todo tipo de público, a pesar de que foron moi lidas por nenas e nenos.

Non obstante, no referente ás obras feministas, non se rastrexa a importación de textos pioneiros, que curiosamente estaban bastante en voga noutros sistemas veciños no mesmo período. Tampoco as autoras con conciencia feminista apostan por ese tipo de obras, como se puido comprobar xa co que se achegou sobre Xohana Torres. O caso de María Victoria Moreno, tradutora prolífica, é aínda máis sorprendente, porque como é sabido ela erixiuse en autotradutora (por exemplo con obras como Natalia: Anagnórisis ou co curioso caso de $A$ néboa-La niebla ${ }^{9}$ ) e tradutora da obra de contemporáneos cos que mantivo unha estreita relación, sendo os casos máis evidentes o da obra de Casares $O$ can Rin e o lobo Crispín, que ela se encargou de verter ao castelán, ou do texto de Helena Villar (tamén no marco da colección A Chalupa de Galaxia, como o anterior) $O$ día que choveu de noite. Cando, a partir de 1988, tivo a oportunidade de dirixir, canda Antonio García Teijeiro e David Otero, a colección "Árbore" de Galaxia, as obras que escolleu ela mesma deixan ver a súa preocupación por dotar o sistema de textos xuvenís de autores contemporáneos ibéricos de calidade: Gabriel Janer Manila, Manuel de Pedrolo e María Àngels Gardella están entre as súas escollas, entre os que se volve coar un clásico como Andersen.

A escasa presenza, entre as súas escollas, xa non de textos feministas, senón tamén de autoras resulta sorprendente nunha creadora que era perfectamente consciente de que ela e as súas contemporáneas (en concreto Helena Villar $^{10}$, Úrsula Heinze ${ }^{11}$, Ana María Fernández e Palmira Boullosa) estaban realizando un traballo pioneiro no marco da literatura infantil e xuvenil: "Nosotras, como otras mujeres de esta tierra que asfaltan carreteras o arriesgan su vida en los trabajos más duros, no vamos a la zaga de los hombres sino a la par, y a veces abriendo camino" (Moreno [1988], apud Pena 2018b: 129).

No que respecta a Sabela Álvarez, o seu traballo vaise centrar, sobre todo, en ser pioneira na crítica de libros infantís en Galicia. Así, percíbese que as súas angueiras tradutolóxicas responderon basicamente a necesidades do sistema, dado que traduciu fundamentalmente nos anos 1979 e 1980 (tempo que coincide tamén co seu período máis creativo como autora) para a colección "A Galea" de Galaxia,

A colección era unha colaboración coa editora catalá La Galera e a vasca Elkar.

Integrado por Carlota Goyta, Asunción Esteban e Anna Vidal.

9 Semella que a obra se escribiu orixinariamente en galego, mais a autora non conseguiu que fose publicada no noso sistema, polo que a publicou primeiramente en castelán en 1985, para en 1999 facelo en galego (para saber máis sobre isto consúltese Pena Presas 2018: 91-92).

10 Helena Villar, se ben contribuíu activamente a construír o campo da literatura infantil e xuvenil galega, así como a renovalo, non escribiu ningún texto que se poida denominar como feminista. Mais, curiosamente, no ámbito da tradución ocupouse fundamentalmente da obra dunha autora de LIX contemporánea: Asul Balzola, que traduciu maioritariamente en 1980, ás veces en colaboración con Xesús Rábade, para Galaxia.

11 Ademais de traducións para o público adulto, nesta época, en ocasións compartindo o traballo con Ramón Lorenzo, traduciu autoras contemporáneas do ámbito lingüístico alemán, como Elisabeth Heck e Mira Lobe. 
especialmente contos clásicos ou adaptacións de narracións populares, tarefa que levaba a cabo con Xosé Xove.

Como se pode comprobar, ningunha das autoras claves para o feminismo na LIX traduce obras que conteñan unha postura claramente a favor da igualdade das nenas e das mulleres. Isto ocorre, con toda probabilidade, porque o sistema galego aínda non estaba importando textos con esta ideoloxía, senón que directamente os estaba creando. Isto non quere dicir que non se coñecesen textos básicos desta tendencia tamén para nenos e nenas. Isto é especialmente evidente no caso de Sabela Álvarez Núñez, que ao realizar a súa laboura crítica di de moitos textos que están feitos "a favor de las niñas", en clara alusión á colección italiana ideada por Adela Turín, da que semella ser boa coñecedora, como tamén se manifesta no seu $O$ rei da nada e outros contos.

Neste período, a tradución parece actuar como unha vía para a acumulación de capital simbólico, sobre todo na literatura xuvenil, xa que se editan textos de clásicos universais como obras que funcionaran particularmente ben con este público en sistemas literarios achegados ao galego (o exemplo paradigmático disto sería a colección Xabarín da editorial Xerais). $\mathrm{Na}$ literatura infantil hai un empeño claro en asentar e recuperar as liñas dos clásicos e dos textos populares, non só da propia tradición, senón tamén das alleas (por exemplo, Francisco Cidrás traduce Heroes, monstros e outros seres da mitoloxía rusa en 1986 para Xerais, nunha colección que precisamente se chamaba Mitoloxías). Porén, os textos feministas, xa existentes e importados por exemplo ao sistema español (Pena Presas 2016a) neste tempo practicamente non están presentes. Isto dá a entender que para os axentes culturais non resultaban fundamentais, polo menos nestes primeiros anos. Isto non é unha sorpresa, dado que a crítica tampouco se ocupa dos textos feministas creados en galego (sirva como exemplo a invisibilidade do relato de Xohana Torres).
Fóra das nosas fronteiras, a que conseguiu ser lida noutras linguas foi María Victoria Moreno $^{12}$, en boa medida porque ocupou unha posición máis preminente no campo literario. Afírmase isto porque axiña dedicou boa parte do seu tempo á literatura infantoxuvenil, como autora mais tamén como tradutora. Igualmente, a súa ocupación de editora de colección en Galaxia forneceulle unha rede de contactos importante, o que favoreceu a exportación das súas obras cara a outros sistemas peninsulares. Por desgraza, agás Anagnórise, as obras feministas en galego deste tempo non foron exportadas por outros sistemas.

\section{Etapa de xeneralización de protagonistas femininas (1990-2005) e aposta pola tradu- ción de autoras}

Este novo período vén marcado porque a literatura infantoxuvenil galega vive un momento de grande expansión: a cada volta son máis as temáticas abordadas, á vez que os escritores e escritoras galegas van acadando máis recoñecemento no seo do estado e aumentan en número. Bo exemplo disto son os dous novos Premios Nacionais de Literatura Infantil e Xuvenil que se unen ao que xa tiña Paco Martín: Cando petan na porta pola noite ${ }^{13}$ (1994) de Xabier Docampo, unha recreación das historias de tradición oral galega, e $O$ misterio dos fillos de Lúa (1995) $)^{14}$ de Fina Casalderrey ${ }^{15}$, unha historia de realismo cotián en que o amor aos animais, a problemática familiar e a tenrura teñen un protagonismo esencial. Non obstante, non será este o único galardón que durante esta etapa obteñan as narradoras e narradores galegos, porque o Premio Lazarillo, o máis antigo de literatura infantil no marco estatal, recaerá en varias ocasións en obras deste sistema literario. Así ocorrerá en $1990^{16}$ con Contos por palabras de Agustín Fernández Paz, en 1999 con $A$ banda sen futuro de Marilar Aleixandre, en 2000 con Chinto e Tom de Gloria Sánchez, en 2001 con Amar e outros verbos de Ana María Fernández e en 2004 con $A$ noite da raíña Berenguela de Xosé Antonio Neira Cruz.

12 Para ver con detalle as traducións da obra de Moreno, pódese consultar Soto e Senín 2018: 133-138.

13 Ademais deste gran recoñecemento, a obra sería incluída na Lista de Honra de IBBY en 1996 e seleccionada no catálogo The White Ravens, da Internationale Jungendbibliotek de Múnic (unha listaxe anual de libros singulares ou especiais que resaltan polas súas cualidades literarias e/ou pictóricas).

14 Anteriormente, en 1994, acadara o Premio Barco de Vapor. Despois de facerse co recoñecemento do Premio Nacional, sería traducido ao catalán e ao castelán na mesma editora.

15 Para saber máis sobre as traducións desta autora, remítese ao artigo de Bará Louro 2020.

16 Neste caso indícanse os anos en que os textos obtiveron o recoñecemento, non a data de publicación. 
O tratamento dos xéneros que fai este grupo de creadoras e creadores é, de maneira xeral, máis igualitario. Desaparecen as imaxes máis estereotipadas que se atopaban na década anterior e aumenta considerablemente o número de personaxes femininas presentes nas obras e a variedade de liñas temáticas en que estas aparecen. Á vez, as ficcións nas que se aprecia o feminismo máis claramente diminúen en número.

Será este un tempo que se caracterice, na súa primeira etapa, por prestar unha especial atención ao lectorado xuvenil, que verá como as coleccións pensadas especificamente para el aumentan. O exemplo paradigmático é o da colección "Fóra de Xogo" de Xerais ${ }^{17}$, creada en 1994, pero neste período tamén estarán a funcionar "Costa Oeste" de Galaxia, a desaparecida "Doce x Vintedous" de Sotelo Blanco, "Alfaguara xuvenil" da editora homónima, "Punto de encontro" de Everest, etc. Este interese polos libros para a mocidade provén, sen dúbida, do aumento na idade de escolarización, que pasa dos 14 aos 16 anos coa nova lei educativa, a $\mathrm{LOXSE}^{18}$, mais tamén na fidelización e no aumento de idade dun lectorado que contaba con libros para si en galego dende que aprendera a ler.

Nesta etapa, Marilar Aleixandre e Agustín Fernández Paz eríxense como autores ponte co feminismo militante, grazas á relevancia que adquiren $A$ expedición do Pacífico (1994) e Rapazas (1994). Se ben a crítica xa reparara nos finais dos anos noventa nun "protagonismo activo do mundo feminino" na ficción galega infantoxuvenil (Gaspar 1999: 62), estas dúas voces creadoras van alén diso, ao facer reflexionar ás súas lectoras e lectores potenciais sobre a discriminación que sofren as mozas e as mulleres en diferentes eidos. Curiosamente, quizais pola relevancia social que acadaran xa a escrita de ambos os dous (especialmente de Fernández Paz, que xa contaba nesta altura co premio Lazarillo, como foi indicado), os seus textos si que se exportan ${ }^{19}$, posibilitando que os modelos que ofrecen se coñezan noutros sistemas. No caso de Aleixandre, o da protagonista, que se disfraza de home para poder participar nunha expedición científica; e no caso de Fernández Paz, os relatos que permiten reflexionar sobre a necesidade da coeducación en todos os ámbitos.

En canto ao tipo de textos que se importan, xeneralízase a tradución de obras de autoras contemporáneas que dan un papel relevante ou alternativo ás mulleres nos seus textos e que, polo tanto, se poden considerar herdeiras do feminismo social. Así, entra a formar parte do campo literario galego nesta etapa a austríaca Christine Nöstlinger, que aparece no sistema galego en 1989 na colección O Barco de Vapor, froito das colaboracións entre Galaxia-SM ${ }^{20}$, con Querida avoa... a túa Susi (traducido por Xulián Maure). Logo virá Horario de clase (1997) en versión de Alberto Álvarez Lugrís para a colección Costa Oeste de Galaxia, ou xa no século XXI un abano moi variado de obras que falan da consolidación da autora entre o público infantoxuvenil. Un camiño moi semellante seguirá a portuguesa Alice Vieira. Tradúcense as súas primeiras obras en 1990, concretamente A lúa non está á venda, que pasa á colección Árbore de Galaxia e de cuxo traballo tradutolóxico se ocupa Antonio Piñeiro, e ao mesmo tempo Rosa, miña irmá Rosa (que sae na colección O Barco de Vapor, sendo a encargada de poñela en galego Xela Arias $^{21}$ ). Despois virá, en 1999, Caderno

17 Nestes momentos, polo número de títulos editados e polas reedicións dos mesmos, pódese dicir que é a máis viva e activa de Galicia para esta franxa de idade.

18 Promulgada en 1990 e en Galicia concretada primeiramente no Decreto 78/1993, de 25 de febreiro, polo que se ve claramente que as coleccións volvían responder, outra volta, ás necesidades do sistema educativo.

19 No caso d'A expedición do Pacífico, tivo versión en castelán por Anaya, traducida pola propia autora só dous anos despois da súa publicación (1996) e tamén en portugués en 1999 da man de don Quixote e en tradución de Fernanda Campos, algo que seguramente pulou o premio da crítica. No caso de Rapazas, tradúcese ao éuscaro (1994), castelán (1996), valenciano (1996) e portugués (1999).

20 A colaboración comezara en 1984 cando acordan publicar conxuntamente tanto literatura infantil e xuvenil (basicamente nas coleccións O Barco de Vapor e Gran Angular), como libros de texto (Pena Presas, 2018b: 96). Mágoa que, por exemplo, a obra Querida Susi, querido Paul, da que é continuación a que se publica en galego, nunca chega a estar dispoñible na nosa lingua.

21 Xela Arias quixo contribuír ao corpus das traducións cara ao galego e salientamos a súa faceta de editora de varias coleccións. A escritora, apenas traducida por causa da súa temperá desaparición, implicouse no proxecto de tradución da editorial Xerais na colección Xabarín, que daquela seguía como criterio fundamental a tradución de textos literarios de autorías clásicas universais para fornecer de lecturas en galego á xente nova. Luna (2017) recoñécea como unha das tradutoras máis activas. 
de Agosto, traducido tamén por Antonio Piñeiro, mais esta vez para Fóra de Xogo de Xerais. Un percorrido parecido é válido para autoras peninsulares que se incorporan un pouco máis tarde ao campo literario galego, como Isabel Clara Simó, Mariasun Landa ou Gemma Lienas.

Non obstante, cómpre chamar a atención de que a xeneralización de autoras traducidas (con proxectos progresistas) se produce xa despois de que as mestras-escritoras do país botaran adiante e renovaran o proxecto da LIX galega. Isto non quita que algúns autores e autoras comprometidos coa igualdade se poidan ver influenciados por algunhas destas escritoras. Este é o caso de Neira Cruz (como se recolle en Luna Alonso 2006), creador consolidado nesta etapa cun habitual interese por visibilizar as personaxes de mozas e pór as súas problemáticas nun primeiro plano. De feito, a investigadora pon como exemplo as concomitancias existentes entre Valdemuller (1998), na que o autor presenta a Mina, que a través dun colgante investiga no pasado da súa familia para crear unha xinea feminina, e a novela $O$ dicionario de Carola (1996) de Carmen Gómez Ojea, na que se narra a historia dunha rapaza que afonda no saber das mulleres que a precederon a través dun obxecto-talismán. Algo semellante sucede con Rosa Aneiros e o seu Ás de bolboreta, un texto xuvenil que narra a historia dun café compostelán, o Luzada, no que van pasando diferentes personaxes que, dende distintos puntos de vista, van contando as súas problemáticas; e a obra de Alice Vieira A lúa non está á venda (1993), na que suceden feitos paralelos. No Lúa, un café lisboeta rexentado por dona Estrela, os clientes van deixando retallos das súas vidas, de maneira que a voz narrativa é cambiante.

No caso da literatura infantil, hai algún exemplo de colección que se viu fondamente influenciada polas traducións que acolleu no seu seo, como por exemplo "O parrulo" de Ir Indo, dirixida por González Barreiro e coordinada por Antón Mascato. Posta en funcionamento no ano 1990, incluíu tanto traducións de obras referenciais de coeducación (o exemplo máis visible é $A$ derradeira Cincenta de
Renata Mathieu, na que unha nena fai as tarefas da casa ata que se rebela), como textos que implicitamente apostaban pola coeducación, como podía ser Dona Carme de Manuel Bragado ou as tres obras publicadas (A cirurxiá, A casa do grilo e a chicharra e $A$ cadela e o óso) por Azucena Arias, que avogan por algo tan sinxelo -á vez que efectivo- como presentar protagonistas do mundo animal de ambos sexos. Aínda así, é preciso incidir na idea de que a colección non estaba especificamente deseñada como "coeducativa", mais semella evidente que os seus responsables si tiñan en conta este criterio.

Para a tradutora e investigadora Patricia Buján (2020: 44):

La traducción de textos de autoras siempre ha sido considerada un elemento básico de la práctica traductiva feminista. Su entrada en los catálogos de las editoriales gallegas con normalidad supone un esfuerzo valorable y un buen avance, incluso aunque en muchos casos falte la mediación necesaria que nos brindarían los peritextos.

Sen dúbida, esta é a etapa na que as autoras traducidas entran con normalidade no campo literario infantoxuvenil. Supoñemos que este fenómeno se debe, en parte, a esa reivindicación dos papeis de nenas e mulleres adultas nas obras escritas orixinalmente en galego, mais tamén se albisca como non houbo unha política tradutolóxica clara, que na maioría das ocasións dependeu de acordos comerciais concretos (velaí o binomio Galaxia-SM, que parece ser un dos grandes potenciadores da publicación habitual de autoras estranxeiras entre nós ${ }^{22}$, pero posiblemente se se analizan os catálogos das editoras estatais con selo galego propio veríase como na maioría das ocasións as traducións de obras de autoras responden a que, previamente, eses textos xa existían no seu catálogo). Só iso explica, por exemplo, como se deixaron para despois obras ben referenciais da literatura infantoxuvenil escrita por mulleres, como pode ser Pippi Mediaslongas, que falou galego en 2017 da man de David A. Alvarez en Kalandraka, ou que sigan faltando outras, como por exemplo Little Women de Louisa M. Alcott.

22 Outro exemplo claro é que na colección Gran Angular (amparada tamén dentro do acordo Galaxia-SM), Casares publica en galego Os escaravellos voan á tardiña en 1989. Non obstante, semella que a escolla non foi autónoma nin proxectada por Galaxia, porque a mesma colección publicara dous anos antes a versión catalá e tres anos antes a castelá. 
No que se refire aos peritextos para presentar e profundar mellor na obra das creadoras importadas, estes foron un ben realmente escaso, por non dicir practicamente ausente. No mellor dos casos, recorreuse a tres ou catro liñas que resumían a traxectoria da autora, iso que Genette (2001: 10) chamou "peritexto editorial". Paga a pena deterse brevemente na escolla destes, polo reveladores que resultan en ocasións. Nunha análise moi superficial compróbase que, mentres algunhas das primeiras coleccións que publicaron traducións habitualmente (como "A Chalupa" de Galaxia) non tiñan ningún dato sobre a autora que estaban a publicar, fose galega ou foránea, a medida que pasa o tempo ${ }^{23}$ semella que se comezan a engadir algúns datos biográficos básicos, conforme á moda editorial do momento. Un bo exemplo é a colección O Barco de Vapor, que optou por engadir na contracuberta unhas poucas liñas sobre as autoras, normalmente referidas á súa data e lugar de nacemento e aos premios obtidos (suponse que por unha cuestión comercial, dado que estes poderían funcionar coma un estímulo para mediadoras e mediadores sen demasiado coñecemento do campo literario):

Christine Nöstlinger naceu en Viena en 1936. Xornalista e escritora de guións para televisión e radio. Foi gañadora do premio Hans Christian Andersen. (Da contracuberta de Querida Susi, querido Paul)

Noutras ocasións, o peritexto editorial é máis longo e está nas lapelas, o que sen dúbida permite contextualizar mellor as autoras, como ocorría na colección Árbore de Galaxia. Porén, nas páxinas iniciais, dábase unha importante contradición: cando se funda a colección, en
1989, os nomes das creadoras aparecían baixo o rótulo "autor" 24 . A comezos dos anos noventa, a editora percibe esta contradición, froito evidente da tradición patriarcal, e corrixe o feito $^{25}$.

Cambiando de ámbito, resulta imposible rematar este apartado sen facer alusión á laboura realizada polas editoriais Kalandraka (fundada en 1998) e OQO (fundada en 2005) para iniciar a reescrita de contos populares dende unha perspectiva feminista, algo que se facía xa na Norteamérica dos anos 70. Así, foron iniciáticas (especialmente OQO) nalgunhas reescrituras de autores galegos, como o exitoso Titiritesa (2006) de Xerardo Quintiá e Maurizio A. Quarello (no que a princesa Wendolina rexeita príncipes azuis, porque ela prefire ser parella doutra princesa) ou Celestino Tarambainas (2005) de Marisa Núñez e Mariona Cabassa (modelo dunha masculinidade disidente). Estas obras acompañaron tamén exportacións, baseadas tamén na reescritura de contos populares, do sistema literario español como o divertido Tres irmás ladroas (2005) de Txabi Arnal. Esta liña provocou unha sorte de contaxio entre outras editoras, que ata ese momento se implicaran escasamente na tradución deste tipo de volumes.

Non obstante, a pesar de que o papel destas dúas editoras no eido da tradución é absolutamente fundamental, como teñen documentado diferentes investigadoras (Fernández Rodríguez 2010: 104), é moi significativo que, no caso da literatura coeducativa, o proceso iniciado por elas transcorrese paseniñamente. Cómpre sinalar, que as súas primeiras edicións en certa maneira reproduciron o acontecido nos comezos do sistema: as escollas repertoriais que se priorizaron son as de publicar contos

23 E non sempre: por exemplo, a editora Juventud, que tamén publicou en galego, non incluía ningún peritexto editorial, como se pode comprobar por exemplo en volumes como A avoíña da maceira de Mira Loebe, que traduciu Xulián Maure en 1990. Tampouco adoitaba incluír información editorial sobre as autorías Edicións do Cumio, que neste tempo tivo unha importante actividade editorial no campo infantoxuvenil.

24 Así se pode comprobar no caso dunha obra dunha autora que escribía orixinalmente en galego: Anagnórise de María Victoria Moreno, mais tamén nas obras traducidas, como ocorría con Úrsula Wolfel, da que Galaxia verteu ao galego Zapatos de lume e sandalias de vento, nunha versión de Rosario Álvarez e Xosé Xove.

25 Desafortunadamente, o de Árbore non é o único exemplo de mala praxe influída polo machismo do mundo literario. A colección Altamar, de Bruño, contaba con información sobre as autoras nas páxinas previas ao inicio da obra. Non obstante, ás veces nestes datos coábanse informacións aparentemente intranscendentes sobre a vida das autoras. Un magnífico exemplo disto é a información que sobre Ana María Magalhães e Isabel Alçada se detalla no seu libro Unha aventura na escola, traducido por Miguel Anxo Murado. O texto, suponse que da autoría dos responsables da editora, ademais de tratalas practicamente como unha única persoa, sinala: "Ambas as dúas viven en Lisboa coas súas respectivas familias. Ana María ten un fillo e mais unha filla. Isabel Alçada só ten unha filla". De novo, o vello prexuízo patriarcal que cingue autoras e literatura infantil por estar estas máis achegadas, supostamente, ao mundo das nenas e mozos debido ao ámbito da maternidade. 
tradicionais universais (nun abano que empeza polos máis coñecidos, como Os sete cabritos, de 1998, para ir dende alí ás culturas máis afastadas da nosa). Ata que consideraron que posúen un capital simbólico de abondo no formato álbum, os seus catálogos non comezaron a posibilitar a reescritura de contos de fadas dende unha perspectiva feminista (mais nótese que isto ocorre xa no período denominado "etapa ecléctica", que se abordará no apartado seguinte). A grande innovación destas editoras veu pola aposta clara polo álbum ilustrado de gran formato, cunha atención moi específica ás ilustracións, e pola publicación simultánea das súas obras en varias linguas peninsulares.

\section{2006-2016. Etapa ecléctica: entre a inno- vación dos textos galegos e a tradución das obras clásicas da coeducación}

Literariamente, neste período, hai que atender ao xurdimento do chamado "Grupo do 1983" (Pena Presas 2018a: 112), é dicir, á incorporación de autores e autoras que tiveron acceso á lingua galega no ensino de maneira regrada e que coñecen moitos dos textos literarios precedentes (tanto creación coma tradución en galego) porque forman parte das súas lecturas de infancia e adolescencia. Este é o caso de Teresa González, Antonio Manuel Fraga, Ledicia Costas, Andrea Maceiras, María Canosa, Erica Esmorís ou Eva Mejuto, cuxas poéticas estaban aínda construíndose en anos anteriores -Costas, Canosa e Maceiras teñen xa unha significativa obra publicada-, para consolidarse pasada a primeira década do século XXI. A este grupo quizais cumpriría engadir tamén a María Reimóndez, se ben ter comezado anteriormente no mundo da escrita, ter dedicado importantes esforzos á literatura para público adulto e o feito de ser unha autora prolífica, fai que as súas características sexan un pouco diferentes.

Varias delas parecen estar destinadas no futuro a ser as voces senlleiras da LIX galega, como así apunta a concesión do Premio Nacional de Literatura Infantil e Xuvenil a Ledicia Costas por Escarlatina, a cociñeira defunta
(2014). Porén, este "Grupo do 83" xa non o constitúen as autoras novas, porque voces como a de Antía Yáñez ou Tamara Andrés, a pesar da súa xuventude e de que a súa produción aínda non é moi abundante, semellan dispostas a apostar por este campo literario.

No relativo ao impacto do feminismo na LIX, hai tres novidosas abordaxes literarias en que a pegada e o impacto do movemento se deixan ver nesta etapa: a presenza de personaxes homosexuais nalgunhas das historias (que afortunadamente seguen a visibilizarse nas novas producións), a fusión do feminismo co multiculturalismo e con outras subxectividades (como as que supoñen un elemento de diferenza engadida) e a formulación de masculinidades disidentes.

Pola súa banda, as traducións multiplícanse exponencialmente, polo que nesta primeira achega resulta complexo observar cal é a dinámica arredor dos textos feministas. Nunha ollada superficial, semella evidente que o campo literario galego está a exportar máis textos ca no pasado, ao que contribúe a proxección que autoras como Ledicia Costas (quizais o caso máis prototípico neste sentido), que apostan por obras claramente enmarcadas dentro do feminismo social, mais tamén foi relevante a singularidade temática de certos volumes, como ocorreu con 22 segundos ${ }^{26}$ de Eva Mejuto, obra que a autora publicou autotraducíndose en Lóguez. Sorprende, porén, que os textos infantoxuvenís de Reimóndez, sempre implicados cos feminismos e co multiculturalismo (velaí Usha ou Corredora), aínda non tivesen a oportunidade de seren traducidos a outras linguas. Non só porque a súa autora é tamén tradutora profesional, senón sobre todo, porque se hai un libro con capacidade para innovar, no que calla a idea das subxectividades *trans, é precisamente o seu Fóra do normal. Na novela non hai só un personaxe *trans, senón unha verdadeira "patrulla trans", tal e como ela a nomea: un grupo de caracteres en completa transición, por unhas cuestións ou por outras. O feito de que as traducións dependan moitas veces da concesión dos premios estatais ${ }^{27}$ e de acordos puntuais entre editoras galegas e foráneas, ao

26 A novela narra a transformación que emprende Álex, un mozo que se decata dende neno da súa identidade trans para se converter, tamén fisicamente, en quen realmente quere ser. O texto constitúe a primeira novela galega para público adolescente sobre esta temática.

27 A novela acadou o I Premio Agustín Fernández Paz pola igualdade, mais o galardón (que neste momento leva dúas edicións e a pesar do seu capital simbólico no seo do sistema polo nome a quen homenaxea) non conta aínda con recoñecemento alén das fronteiras galegas. 
que cómpre sumar que o tema resulta rompedor e tabú para os sectores máis reaccionarios, pode explicar que as personaxes de Reimóndez non falasen, polo momento, outras linguas. A isto habería que engadir unha certa perda de diálogo entre o sistema literario en castelán e as outras linguas peninsulares, que semella manifestarse nun aparente desinterese sobre o que se publica noutros idiomas do estado. Tamén, porque ás editoras lles adoitan faltar persoas de referencia que lles sirvan de intermediarias para ler na lingua orixinal. Igualmente, un desfase importante entre a data de publicación no idioma de partida e a posible saída ao mercado noutro campo literario fai que, en ocasións, ás editoras de destino ese título lles deixe de interesar, porque consideran que o territorio onde ía ter máis impacto xa foi, dalgunha maneira, "amortizado". Estas cuestións loxicamente, afectan ás autoras e autores que escriben en galego, catalán e euskera.

Por fin, na segunda década do século XXI, cómezase a verter ao galego os grandes clásicos da coeducación, nomeadamente os títulos máis coñecidos da colección "A favor de las niñas". Así foi como se traduciu en castelán, en concreto na editorial Lumen que dirixía Esther Tusquets, a colección italiana "Dalla parte delle bambina", ideada por Adela Turín en Milán en 1975, escrita por ela mesma e ilustrada por Nella Bosnia. A colección publicou máis de vinte libros, traduciuse a diversos países europeos e a súa recepción foi sorprendentemente polémica (Pena Presas 2016a). En galego, pódese atopar en Kalandraka dende 2012, cando se publicou Artur e Clementina, traducida por Eva Almazán. Na contracapa, a editora, que chama esta serie de libros co nome da súa autora principal, incorpora un breve peritexto que explica a relevancia desta sinalando que é "unha colección de referencia para a coeducación e a igualdade". A editora pontevedresa tamén incorpora ao seu catálogo en 2011 A coelliña Marcela de Esther Tusquets, con ilustracións de María Hergueta, que resulta ser outra das obras clásicas da igualdade para a infancia no Estado español. Publicada orixinalmente en 1980, o encargado de vertela ao galego é Xosé Ballesteros. Isto, que cumpriría completar con toda a serie de Pippi Mediaslongas á que xa se aludiu anteriormente, alén de responder ao propio pulo das novas obras creadas, ten que ver coa política de recuperación de álbums ilustrados clásicos iniciada por Kalandraka nos últimos tempos. Mais tamén coa crecente (ata o momento) conciencia social arredor do feminismo ou mesmo co efecto que puido ter o artellamento de coleccións coeducativas "made in Galicia", como "Contos da igualdade" (Baía, 2006), "Lila Lilaina" (A Nosa Terra, 2008) ou "A igualdade conta" (Embora, 2010).

Así mesmo, nesta etapa chama tamén a atención a publicación en galego de obras xuvenís feministas contemporáneas, da que é un magnífico exemplo a serie Poderosa de Sérgio Klein (2008-2013, con 3 volumes saídos do prelo en tradución de Mercedes Pacheco), que mestura habilmente o humor coa fantasía ao contarnos, en forma de diario, a vida de Joana, unha rapaza que ten un superpoder: todo o que escribe coa man esquerda se volve realidade ${ }^{28}$. Outra boa aposta é $A$ evolución de Calpurnia Tate (2013) de Jackeline Kelly (traducida por Carlos Azevedo), novela da que Kalandraka, baixo o seu selo Faktoría K, tamén publicou o volume que lle dá continuación. Neles, unha rapaza de finais do século XIX desafía a súa familia ao interesarse polo mundo das ciencias e das convencións sociais reservadas para o seu xénero. Nesta mesma liña habería que resaltar obras de fronteira como A casa de Mango Street (2008) de Sandra Cisneros, traducida por Alicia Meléndez en Sushi Books, ou editada tamén baixo o mesmo selo, Todos deberiamos ser feministas de Chimamanda Ngozi Adichie; ademais de Bicame, profe (2008) da xaponesa Kazuma Kodaka, o primeiro manga que se edita traducido grazas a edicións do Cumio. A pesar de que seguen a aparecer obras dun marcado cariz feminista, estase deixando a un lado, moi especialmente, a innovación no referido ás masculinidades alternativas (especialmente na novela xuvenil, mais non tanto no álbum ilustrado), a homosexualidade e a transexualidade (non deixa de ser moi significativo, que ata o de agora ningunha das obras traducidas apostase por presentar a un protagonista con esta identidade). Agardemos que, neste sentido, non se cumpra a "demora" máis que evidente acontecida coa tradución das obras feministas.

28 Aínda así, a escolla deste texto parece non estar especialmente formulada e ser froito de que Anaya (á que pertence Xerais) publicara xa, previamente, a obra en castelán e en catalán (baixo o selo de Bromera). 
No propio sistema, dentro do ámbito infantoxuvenil, estanse xa a dar fenómenos relacionados coa tradución en clave feminista que, ás veces, poden pasar desapercibidos. Así, na editora Patasdepeixe, dedicada á tradución de álbums infantís, interpretouse dende unha perspectiva "a favor das nenas" o libro A filla do Grúfalo de Julia Donaldson e Axel Scheffler, traducido ao galego por Piño Sáez e Laura Sáez. Como conta a súa tamén editora, Laura Sáez (2020: 203-204), tanto o título orixinal, con ese substantivo non marcado xenericamente, The Gruffalo's Child, coma as ilustracións, posibilitaban que o animal protagonista fose de sexo masculino ou feminino. Optouse pola segunda opción dado a independencia e a valentía que demostra a personaxe principal, o que pode ser un elemento de alento para as lectoras do álbum. A literatura como contrapunto ao que ás veces se percibe na sociedade. Así, a perspectiva feminista convértese nun dos filtros da editora, froito do traballo anteriormente realizado.

Por todo isto, as perspectivas para este comezo da terceira década do século XXI debesen ser esperanzadoras, sempre que os diferentes axentes do sistema literario sexamos quen de reflexionar sobre o que se está a publicar (aínda que non só no apartado de traducións). Polo momento, obsérvase que obras feministas contemporáneas, consolidadas noutras literaturas -pola súa boa aceptación polo público ou/e crítica- van chegando pouco e pouco ${ }^{29}$. Asemade, as autoras de LIX seguen sendo importadas ao campo literario galego, mais en non poucas ocasións debido a unha sucesión de casualidades entre as que se mesturan o feito de que esa autora xa conta con obra no catálogo da editora que o traduce (ou se dá a casualidade de que a creadora está noutros selos do grupo ao que pertence a editora galega), un interese persoal da tradutora ou tradutor por verter determinado texto ao galego e/ou que o texto fose galardoado con algún premio senlleiro na súa cultura de orixe. Aínda así, sería necesaria unha reflexión conxunta sobre o que se traduce e o que non, ademais de reparar en como se traduce, tal e como sinala Patricia Buján:

...estamos en un momento en que ya nos deberíamos plantear qué autoras publicamos en traducciones y cómo, y aquí echamos en falta una política editorial feminista consciente y generalizada. Asumimos que, dada nuestra situación diglósica y la dificultad de afianzar lectorado en gallego entre el público adulto, nos topamos con la dialéctica de ofrecer todo tipo de contenidos en gallego para ganar lectores (contenidos que, por cierto, se encuentran ya en el polisistema, bien por existir creación original en gallego, bien por haber traducción en lenguas próximas) frente a ofrecer literatura innovadora que implique un esfuerzo de lectura. En este sentido, los agentes del campo literario (tanto en producción como en crítica) deberían quizás dirigir su esfuerzo más a la comunicación de las obras y crear un discurso en torno a la traducción y a su capacidad para construir un nuevo sistema de valores. (2020: 44-45)

Para o público infantoxuvenil rexen outras dinámicas, sobre todo dende a perspectiva de que o esforzo de lectura non é, habitualmente, ben valorado polos axentes mediadores -especialmente nos que prima o enfoque educativo. Ademais, hai que ter tamén en conta que o lectorado en formación en escasísimas ocasións recorre ao portugués e en moitas ao castelán, de aí a importancia de dispoñer de material diverso en galego. Porén, ter a capacidade (e a valentía) de facer unha reflexión colectiva sobre que obras é urxente traducir, cales é necesario e con que perspectivas de futuro se segue a construír este campo literario semella máis que necesario nun futuro inmediato. Parece, en certa medida, que a falta de planificación nas traducións que se importaban de literatura para público adulto tamén impregnou o ámbito das traducións de LIX. Nel, trasladar textos dunha lingua a outra tivo que ver coa procura do capital simbólico a través de obras clásicas (dun canon marcadamente masculino, porque se non non se explica a serodia entrada das obras feministas traducidas no sistema galego) mais tamén a cuestións vencelladas coas relacións persoais ou coa propia casualidade.

29 Quizais sexa isto máis evidente nos textos para público adulto e sinálanse varios exemplos que parecen especialmente significativos: Feminismo para o 99\%. Un manifesto de Cincia Aruzza, Tithi Bhattacharya e Nancy Fraser, editado por Catroventos en tradución de Patricia Buján; Como ser muller ou Como se fai unha rapaza de Caitlin Moran, editado por Rinoceronte en tradución de Estela Villar Nogueira; O conto da criada de Margaret Atwood, vertido ao galego por Celia Recarey e Carlos Valdés en Irmás Cartoné; As confesións dunha filla do século de Donna Paola, en versión de Isabel Soto en Hugin e Munin ou A cámara do sangue e outros relatos de Angela Carter, traducido por María Reimóndez en Urco. 


\section{Conclusións: transformar os mapas}

A exclusión da literatura escrita por mulleres no canon foi o primeiro elemento que provocou que as obras feministas e/ou coeducativas doutros sistemas literarios tardasen en publicarse en lingua galega, xa que o noso propio campo literario estaba nunha tentativa de acumular capital simbólico, para o que se comezou por recorrer a contos populares e contos tradicionais (primeiro das tradicións máis achegadas, para logo recorrer ás máis diferentes) e pasar logo a textos canónicos da historia da literatura infantil. Sobre isto hai xa opinións controvertidas: Mociño (2015) considérao unha vía de consolidación de novos modelos literarios - especialmente na literatura xuvenil-, porén, Galanes (2010) móstrase reticente a este procedemento, dado que insiste no perigo de dependencia sobre o sistema A, incidindo en que esa tradución masiva só ten sentido nun contexto de necesidade da lingua (o propio cambio no marco legal). Sexa como for, no campo literario infantil de noso, as obras feministas e coeducativas chegaron antes pola vía da propia creación, que pola importación de modelos externos, aínda que xa se sinalaron algúns casos en que textos galegos feministas se ven claramente influenciados por producións doutros sistemas veciños, nomeadamente o castelán e o portugués, que tradicionalmente funcionaron (e funcionan) como vía pola que chegan as novidades editoriais. $\mathrm{O}$ mesmo semella estar ocorrendo coas masculinidades disidentes, o tratamento das identidades sexuais non normativas e os personaxes *trans: mentres que temos xa claros exemplos de obras propias que apostan por normalizar personaxes nesas diatribas, seguen faltando traducións que acheguen o que ocorre noutros sistemas literarios e que nos fornezan novos exemplos.

Ademais, faise evidente que hai unha grande distancia entre a data de aparición no sistema orixinal e de tradución para o sistema galego de obras clásicas coeducativas e feministas, sendo o caso máis palpable o da colección A favor de las niñas, pero tamén sorprende a pouca (e tardía) incidencia de escritoras clásicas, como Astrid Lindgrem, Ana María Machado, Margaret Brown ou Beatrix Potter $^{30}$. Se González Barreiro (2010) falaba dun atraso de máis de vinte anos sobre traducións de clásicos na LIX, no caso das obras coeducativas o desfase é de máis de trinta. Asemade, seguen existindo baleiros sorprendentes, como pode ser a falta de Histoire de Julie, que avait une ombre de garçon de Christian Bruelle e Anne Galland ou The Paper back Princess de Robert Munsch, por citar tan só algúns dos máis coñecidos. Isto explica, en grande medida, a aparencia de desactualización que achegan moitas bibliografías coeducativas actuais, que seguen recorrendo aos textos tradicionais de coeducación en castelán e sinalan tan só uns poucos títulos en galego (o que tamén amosa a dificultade do sistema para visibilizarse).

Así mesmo, aínda que as autoras feministas exerceron de tradutoras (moi especialmente nos inicios do sistema, aínda que hai outros casos como o de Aleixandre que excede ese período), non o fixeron de obras feministas infantís, senón que atenderon as demandas que este parecía establecer en cada momento (tamén porque, en moitas ocasións, a escolla non dependía delas, senón que respondía a encargas editoriais). Porén, como se demostrou, coñecían moitas destas obras a través do sistema A (fundamentalmente, o castelán).

Igualmente, as reescrituras dos contos de fadas, tan comúns noutros sistemas literarios, só se posibilitan a partir da década dos 2000, coa "apertura" de OQO e Kalandraka cara a esta cuestión. Non obstante, a estratexia seguida por ambas editoras en canto a políticas tradutolóxicas sobre obras coeducativas segue a liña do conxunto do sistema: primeiro o "capital", logo a "coeducación", o que tamén hai que vencellar co auxe desta cuestión en Galicia.

Aínda que en xeral a exportación de textos propios non era o obxecto central desta reflexión, cómpre subliñar a paseniña visibilización do sistema literario galego fóra das nosas fronteiras a través da exportación, por parte doutros sistemas -especialmente dos peninsulares-, de obras feministas, como pode ser o caso de Anagnórise (seguramente esta escolla repertorial se produciu como resultado de que é unha novela de problemática adolescente, nun tempo en que estas non eran especialmente abondosas), Rapazas ou $A$ expedición do Pacífico. Segundo Fernández Rodríguez (2012: 197) este é un fenómeno que se estende á achega que as autoras galegas fixeron pola visibilización da literatura no exterior e que en parte se produciu pola innovación creadora. No referido, concretamente, ás autoras de LIX, a investigadora constata unha crecente

30 Por non falar da total ausencia de textos de autoras procedentes de sistemas menos centrais. 
visibilización destas. Isto reforza a idea de que a tradución non funcionou aquí como un estímulo para a renovación, senón máis ben como un mecanismo de lexitimación dos propios modelos que xa estaban funcionando no sistema literario.

Por esta achega, parece claro que dende os poderes públicos non se deu un grande peso a axudar a verter ao galego textos coeducativos procedentes doutras literaturas, mais que as editoras tampouco apostaron maioritariamente por facelo. En que medida a etiqueta de "ideoloxizados" puido pexar as obras feministas? Neste sentido, semella que levar a cabo a proposta de Montero Küpper sería fundamental:

...insistir en la posibilidad de elegir aquellos textos literarios incluso cuando no figuren en un "repertorio hegemónico". (...) Abandonar la hegemonía cultural significaría colocarnos en una situación privilegiada ya que nos permite ampliar nuestro horizonte cultural completando con importaciones el espectro literario y científico que ofrece la cultura dominante. (2015: 41)

Esta estratexia permitiríanos acceder a uns outros textos coeducativos, ou é que as literaturas non centrais non contan con eles? Esta, quizais, é outra das grandes batallas dos vindeiros anos: para renovar o imput dos textos galegos, para contar con modelos alternativos, para actualizar as bibliografías dirixidas a mediadoras ou o que é o mesmo, para transformar as prácticas educativas e polo tanto posibilitar o cambio social, a tradución de textos na marxe -por escollas repertoriais e por posición do seu propio sistema de orixe- pode ser un convite a que entre o vento e o remexa todo, para transformalo.

\section{Referencias bibliográficas}

Bará Louro, Sabela (2020): “Autotraducción y traducción ajena: Fina Casalderrey”, Transfer 15/1-2, pp. 251-275, http://revistes.ub.edu/index.php/transfer/article/view/30211/30425.

Blanco, Carmen (1990): Literatura galega da muller. Vigo: Xerais.

Buján Otero, Patricia (2020): "He aquí la vida de una mujer literata. Traducción y género en las políticas editoriales en Galicia", Transfer 15/1-2, pp. 31-51, http://revistes.ub.edu/index.php/transfer/article/ view/30193.

Castro, Olga e Emek Ergun (2017): "Introduction: Re-Envisioning Feminist Translation Studies. Feminisms in Translation, Translations in Feminism", en O. Castro e E. Ergun (eds.), Feminist Translation Studies. Local and Transnational Perspectives. London: Routledge, pp. 1-11.

Domínguez Pérez, Mónica (2008): Las traducciones de literatura infantil y juvenil en el interior de la comunidad interliteraria especifica española (1940-1980). Tese de doutoramento (dirixida por Blanca Ana Roig Rechou e Fernando Cabo Aseguinolaza). Santiago de Compostela: Universidade de Santiago de Compostela.

Fernández Rodríguez, Áurea (2006): "La voz femenina traducida. Literatura feminista versus literatura de mujeres”, en Á. Fernández Rodríguez, I. Galanes Santos, A. Luna Alonso e S. Montero Küpper (eds.), Traducción de una cultura emergente. Bern: Peter Lang, pp. 177-199.

(2010): “La traducción en Galicia y la industria editorial (1980-2008)”, en E. Gallén, F. Lafarga e L. Pegenaute (eds.), Traducción y autotraducción en las literaturas ibéricas. Bern: Peter Lang, pp. 93-107. (2012): "La voz femenina traducida: literatura feminista versus literatura de mujeres", en A. Fernández Rodríguez, I. Galanes Santos, A. Luna Alonso e S. Montero (eds.), Traducción de una cultura emergente: la literatura gallega contemporánea en el exterior. Berna: Peter Lang, pp. 177-199.

Fernández Rodríguez, Áurea e Ana Luna Alonso (2020): "Nós-outras. Comportamentos e intervencións tradutivas. Unha revisión crítica permanente", Transfer 15/1-2, pp. 1-11, http://revistes.ub.edu/index. php/transfer/article/view/30188.

Galanes Santos, Iolanda (2010): "Panorama da literatura traducida en Galicia (1980-2008): fluxos literarios peninsulares”, en E. Gallén, F. Lafarga e L. Pegenaute (eds.), Traducción y autotraducción en las literaturas ibéricas. Bern: Peter Lang, pp. 109-124.

_- (2015): "Literaturas extranjeras en la cultura gallega", en Á. Fernández Rodríguez, I. Galanes Santos, A. Luna Alonso e S. Montero Küpper (eds.), Literaturas extranjeras y desarrollo cultural. Hacia un cambio de paradigma en la traducción literaria gallega. Bern: Peter Lang, pp. 43-61.

Gaspar, Silvia (1999): “Títulos e autores que marcan un século de LIX”, Fadamorgana 2, pp. 60-69.

Genette, Gérard (2001): Umbrales. México: Siglo XXI. 
Luna Alonso, Ana (2006): "La proyección de la literatura infantil y juvenil gallega a través de la traducción”, en Á. Fernández Rodríguez, I. Galanes Santos, A. Luna Alonso e S. Montero Küpper (eds.), Traducción de una cultura emergente. Bern: Peter Lang, pp. 129-148.

(2017): "O papel da tradutora no campo literario galego", Madrygal. Revista de Estudos Galegos 20 Núm. Especial, pp. 147-156, https://revistas.ucm.es/index.php/MADR/article/view/56228.

Magalhães, Ana María e Isabel Alçada (1993): Unha aventura na escola. A Coruña: Bruño.

Mociño González, Isabel (2015): "Literatura infantil y juvenil gallega: la importación de traducciones", en Á. Fernández Rodríguez, I. Galanes Santos, A. Luna Alonso e S. Montero Küpper (eds.), Literaturas extranjeras y desarrollo cultural. Hacia un cambio de paradigma en la traducción literaria gallega. Bern: Peter Lang, pp. 105-126.

Montero Küpper, Silvia (2015): "Situación de partida y análisis de las iniciativas de apoyo a la traducción en Galicia”, en Á. Fernández Rodríguez, I. Galanes Santos, A. Luna Alonso e S. Montero Küpper (eds.), Literaturas extranjeras y desarrollo cultural. Hacia un cambio de paradigma en la traducción literaria gallega. Bern: Peter Lang, pp. 15-41.

Nodelman, Perry (1988): "Literary Theory and Children's Literature. Children's Literature as Women Writing”, Children's Literature Association Quartely 13/1, pp. 31-34.

Nöstlinger, Christine (1989): Querida Susi, querido Paul. Vigo: SM / Galaxia.

Paul, Lisa (1987): “Enigma Variations: What Feminist Theory Knows about Children's Literature", Signal 53, pp. 180-202.

Pena Presas, Montse (2010): “A muller contra a marea. Xohana Torres pioneira da literatura infantil galega”, Grial 188, pp. 18-25.

(2016a): Feminismo, xénero e coeducación na literatura infantil e xuvenil: historia crítica e aplicación didáctica. Tese de doutoramento (dirixida por Dolores Vilavedra Fernández e Bieito Silva Valdivia). Santiago de Compostela: Universidade de Santiago de Compostela.

(2016b): "Soñar sen cancelas: Manuel María e a construción dunha educación literaria en galego", Boletín da Real Academia Galega 377, pp. 155-168, http://publicacionsperiodicas.academia.gal/index. php/BRAG/article/view/503/517.

- (2018a): Feminismos e literatura infantil exuvenil en Galicia. Santiago de Compostela: Laiovento. (2018b): A voz insurrecta. Vigo: Galaxia.

Sáez Fernández, Laura (2020): "Editorial Patasdepeixe: breve análisis del catálogo y políticas de edición y traducción desde una perspectiva feminista", Transfer 15/1-2, pp. 191-206, http://revistes.ub.edu/index. $\mathrm{php} /$ transfer/article/view/30199.

Shavit, Zohar (1986): Poetics of Children's Literature. Athens: The University of Georgia Press.

Soto, Isabel e Xavier Senín (2018): María Victoria Moreno: sementadora de futuro. Vigo: Xerais. 